\title{
A Review of Paulownia Biotechnology: A Short Rotation, Fast Growing Multipurpose Bioenergy Tree
}

\author{
Niraj Kumarmangalam Yadav ${ }^{1 *}$, Brajesh Nanda Vaidya ${ }^{{ }^{*}}$, Kyle Henderson ${ }^{1}$, Jennifer Frost Lee ${ }^{2}$, \\ Whitley Marshay Stewart ${ }^{1}$, Sadanand Arun Dhekney ${ }^{3}$, Nirmal Joshee ${ }^{1 \#}$
}

\begin{abstract}
${ }^{1}$ Agricultural Research Station, Fort Valley State University, Fort Valley, USA; ${ }^{2}$ Wesleyan College, Macon, USA; ${ }^{3}$ Department of Plant Sciences, University of Wyoming, Sheridan Research \& Extension Center, Sheridan, USA.

Email: josheen@fvsu.edu
\end{abstract}

Received August $5^{\text {th }}, 2013$; revised September $5^{\text {th }}, 2013$; accepted October $1^{\text {st }}, 2013$

Copyright (C) 2013 Niraj Kumarmangalam Yadav et al. This is an open access article distributed under the Creative Commons Attribution License, which permits unrestricted use, distribution, and reproduction in any medium, provided the original work is properly cited.

\begin{abstract}
Paulownia is a genus of fast-growing and multipurpose tree species that is native to China. Due to their rapid growth and value in the timber market, many Paulownia species are cultivated in several temperate zones worldwide. Economic importance of Paulownia is increasing as new uses and related products are developed. It is also suitable as a lignocellulosic feedstock crop for the bioethanol industry in the Southeastern USA. A number of Paulownia species are valuable sources of secondary metabolites including flavonoids with high antioxidant activities. A high demand for planting material in domestic and international markets for afforestation and bioenergy production has necessitated the development of efficient micropropagation protocols for rapid and mass propagation of Paulownia. Over the past several decades, research on Paulownia species has been conducted to develop micropropagation, somatic embryogenesis and genetic transformation protocols for use in agroforestry and reforestation programs. Given the economic importance and current and potential future uses of Paulownia, this paper reviews the development of biotechnological approaches for plant propagation and genetic improvement, and antioxidant potential of secondary metabolites occurring in species.
\end{abstract}

Keywords: Micropropagation; Biofuel; Plant Growth Regulator; Regeneration; Somatic Embryogenesis;

Transformation; Antioxidant Potential

\section{Introduction}

Paulownia is a deciduous, fast growing, hardwood tree (family Paulowniaceae, previously in the family Scrophulariaceae) comprised of nine species and a few natural hybrids that are native to China [1]. Important species in this genus include $P$. albiphloea, $P$. australis, $P$. catalpifolia, P. elongata, P. fargesii, P. fortunei, P. kawakamii, and P. tomentosa [2]. Paulownia species are found growing naturally and under cultivated conditions in several parts of the world including China, Japan and Southeast Asia, Europe, north and central America, and Australia. Species in the genus are extremely adaptive to wide variations in edaphic and climatic factors, and grow well on lands deemed marginal. In China, Paulownia grows in regions from the plains to elevations up to 2000 feet [2]. It exhibits a number of desirable characteristics

\footnotetext{
${ }^{*}$ These authors contributed equally to the manuscript

${ }^{\#}$ Corresponding author.
}

such as rot resistance, dimensional stability and a high ignition point [3], which ensures the popularity of its timber in the world market [4,5]. For decades, Japanese craftsmen have utilized it as revered wood in ceremonial furniture, musical instruments, decorative moldings, laminated structural beams and shipping containers. The tree made its way to the United States during the mid$1800 \mathrm{~s}$ in the form of seed, which was as packaging material for delicate porcelain dishes [5]. Once unpacked, the tiny seeds were dispersed by wind and naturalized throughout the eastern states. Paulownia cultivation for timber production is an unorganized but emerging enterprise in the US and gaining importance because of the strong demand in Japan and some other countries. The total consumption of Paulownia wood in Japan was approximately 17 million board feet (MBF) during 19711973. In a few years imported Paulownia wood volume increased from $16 \%$ to $60 \%$ of total consumption [6]. With a shift in paradigm in favor of alternative fuels, a 
change from food and feedstock to non-food and feedstock sources for cellulosic ethanol is mandatory. The US has already mandated a goal of producing 36 billion gallons of biofuels by 2022 via the Renewable Fuels Standard, RFS2 [7].

In recent years, molecular and genetic engineering techniques have gathered momentum in forest tree research for industrial use and assistance with reforestation and forest management programs. Paulownia species have received due attention in tree-tissue culture owing to their multifaceted significance. In vitro propagation has ensured that the growing demand for superior planting material, biomass and forest products is met. A number of factors including explant selection, macro- and micronutrient composition, incorporation of plant growth regulators, antioxidants, additives and adsorbents during in vitro culture have been optimized to develop successful regeneration protocols for several Paulownia species. This review attempts to highlight the current procedures available for in vitro propagation of Paulownia species and their applications in genetic engineering for crop improvement. Additionally, antioxidant capacity of leaf extract from two Paulownia species for their potential medicinal value is also reviewed.

\section{A Multipurpose Tree}

Under natural conditions a 10 year old Paulownia tree measures $30-40 \mathrm{~cm}$ diameter at breast height (dbh), and contains a timber volume of $0.3-0.5 \mathrm{~m}^{3}$ [2]. Paulownia timber is lightweight, yet strong, dries rather rapidly and has an aesthetically pleasing light colored grain that does not warp, crack, or deform easily. In addition, the wood is easily worked, suitable for carving and has excellent insulation properties [2]. Several species have been planted extensively in Australia to meet demand for timber [8]. Due to its rapid growth and high cellulose content (440 g.cellulose $/ \mathrm{kg}$ ) studies have been conducted to evaluate its suitability for solid biofuel and cellulose pulp industry [9]. P. elongata wood fillers are successfully employed to create biodegradable bio-composite with poly lactic acid (PLA), introducing a new product in the market [10]. Paulownia wood flour filler produced composites that had comparable or superior mechanical, flexural, and impact strength properties to composites of pine wood flour filler [11]. A recent study showed that $P$. elongata wood flour could be utilized in the production of the filled polypropylene composites [11]. Paulownia flowers and leaves are a good source of fat, sugar and protein, and utilized as fodder for pigs, sheep and rabbits [2]. The nitrogen content in Paulownia leaves can be compared favorably with some leguminous plants. Paulownia leaves are used as a green manure crop by farmers in Kwangsi, China. Paulownia is used to treat various ailments in traditional Chinese medicine due to medicinal compounds it contains [2]. Paulownia inflorescences are large in size and a good source of honey [2]. Paulownia has been capitalized for agroforestry [12,13], biomass production [14], land reclamation [15], and animal waste remediation [16]. Various attributes of Paulownia are summarized in the Figures 1(A)-(I).

\section{Potential Biomass Crop}

Greater than 30 million acres of woodland, and idle pasture and cropland exist in the southeast United States, and much of this land could potentially be used to produce valuable tree-crops, Paulownia being one of them [17]. Due to the fast growth and coppicing property (Figure 1(D)), its potential as a biofuel crop has been extensively studied $[10,18,19]$. A major advantage of using biomass as a source of fuels or chemicals is its renewability. Wood from forest trees modified for greater cellulose or hemicelluloses could be a major feedstock for fuel ethanol. In a biomass comparison study performed in Germany, P. tomentosa $\left(12.7\right.$ tons $\left.\cdot \mathrm{ha}^{-1}\right)$ out-produced Salix viminalis $\left(8.2\right.$ tons $\left.\cdot \mathrm{ha}^{-1}\right)$ on short rotation coppice under dry land conditions [20].

An evaluation of Paulownia wood revealed the composition to be $14.0 \%$ extractive, $50.55 \%$ cellulose, $21.36 \%$ lignin, $0.49 \%$ ashes, $13.6 \%$ hemi-cellulose [19]. Ongoing research at Fort Valley State University (FVSU) has determined that the harvestable biomass of Paulownia elongata after 30 months (after three growing seasons) is almost $92 \mathrm{~kg} /$ tree (unpublished results). Under favorable conditions, an intensive plantation of 2000 trees per ha can yield up to 150 - 300 tons wood annually, only 5 - 7 years after planting [21]. Additional studies are required to study biomass potential in variable soils and climates.

Paulownia produces many fine winged seeds (up to 2000 seeds per fruit) weighing about 5000 seeds per gram [21]. Scanning electron microscopy of seeds reveal an extensive network of fine tubes that may play an important role in maintaining structural integrity of the wing to assist with wind dispersal, and create water channels for promoting seed germination (Figures 1(A) and (B)). Seedling development studies indicate that a 16 $\mathrm{h}$ photoperiod is optimum for leaf production, stem elongation, root elongation, and total dry mass accumulation [22]. Seeds sown in a greenhouse germinated in as little as one week, with true leaf emergence within two weeks after germination. Lipids in $P$. tomentosa seed extract consist of linoleic $(64.1 \%)$, oleic $(21.2 \%$ and palmitic acids (7.3\%). $\gamma$-Tocopherol (approx. 100.0\%) predominated in the tocopherol fraction, and in the sterol fraction $-\beta$-sitosterol (79.2\%), campesterol (10.3\%) and stigmasterol $(7.7 \%)$ were the dominant components. Though lipid profile of seeds is suitable for biodiesel 


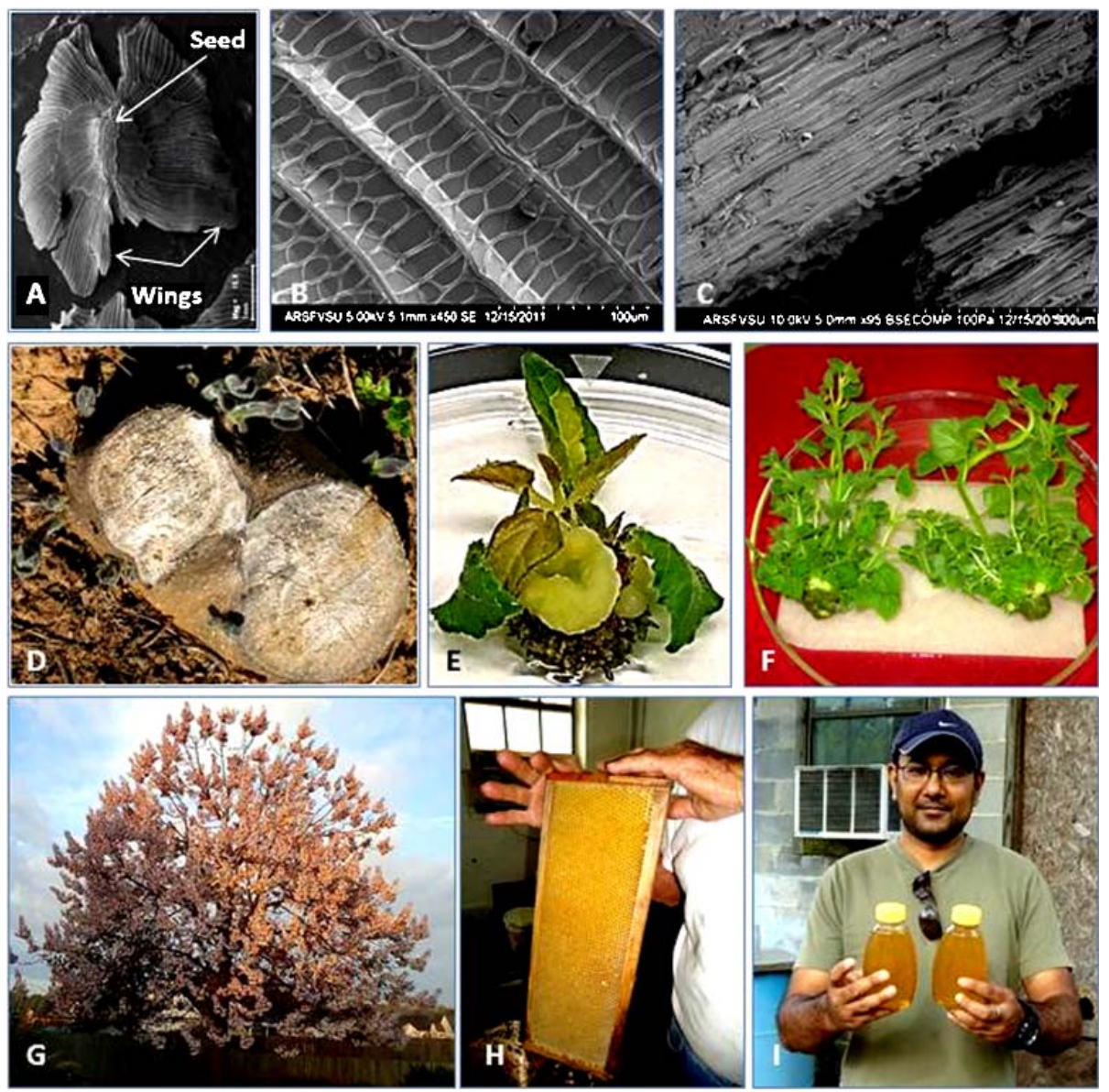

Figure 1. Paulownia elongata as a multipurpose tree for SE USA. (A) Scanning electron micrographs (SEM) of a seed, (B) SEM of Paulownia elongata seed (wing) exhibiting structural organization to support dispersal, (C) SEM of unaltered ground wood, (D) One-year-old tree exhibiting coppicing potential after cutting, (E) and (F) Micropropagation protocols resulting in multiple adventitious shoot generation for commercial mass production, (G) A seven year old tree blooming in Central Georgia, USA, (H) and (I) Scope for monofloral honey production as trees bloom for $\mathbf{4}$ - 6 weeks.

production, it would potentially be labor-intensive due to high number of small seed production. Seeds contain $10.6 \%$ protein, $9.5 \%$ cellulose and $38.2 \%$ hydrolysable carbohydrates [23]. Research addressing development of a suitable machine for fruit/seed collection and further processing would be required to make this aspect a reality.

\section{Plant Regeneration and Genetic Transformation in Paulownia}

Documented proof of plant tissue culture work on Paulownia spans little over three decades and are presented in the Table 1. Various aspects of plant tissue culture dealing with callus induction, micropropagation, protoplast culture, somatic embryogenesis and the need of a reproducible regeneration system for genetic transformation of the plant is discussed below.

\subsection{Organogenesis and Micropropagation}

Paulownia is conventionally propagated using seed and root cuttings. Seed propagation is not reliable due to presence of seed borne pathogens and pests, poor seed germination and altered growth habit. Additionally, seedling growth is slow compared to root cutting-derived plants $[4,24]$. Propagation by root cuttings pose limitations as these can be a potential source of pathogens.

An efficient plant regeneration system (Figures 1(E) and $(\mathbf{F})$ ) is a prerequisite for transgenic plant production and further studies. Micropropagation protocols have been established for a number of Paulownia species (Table 1) including $P$. catalpifolia [25,26], $P$. elongata [27,28], P. fortunei [29-34], P. kawakamii [35-38], P. taiwaniana [39-41] and $P$. tomentosa [29-31,37,38,4245]. Most protocols developed to date predominantly use nodal explants. Another explant used successfully, though to a lesser extent, is petiole with cut leaf [46]. Callus production and plant regeneration via organogenesis was observed in $P$. fortunei shoot tip explants cultured on MS medium containing $4.4 \mathrm{mg} \cdot \mathrm{L}^{-1}$ thidiazuron (TDZ) for 4 weeks followed by transfer to MS medium 


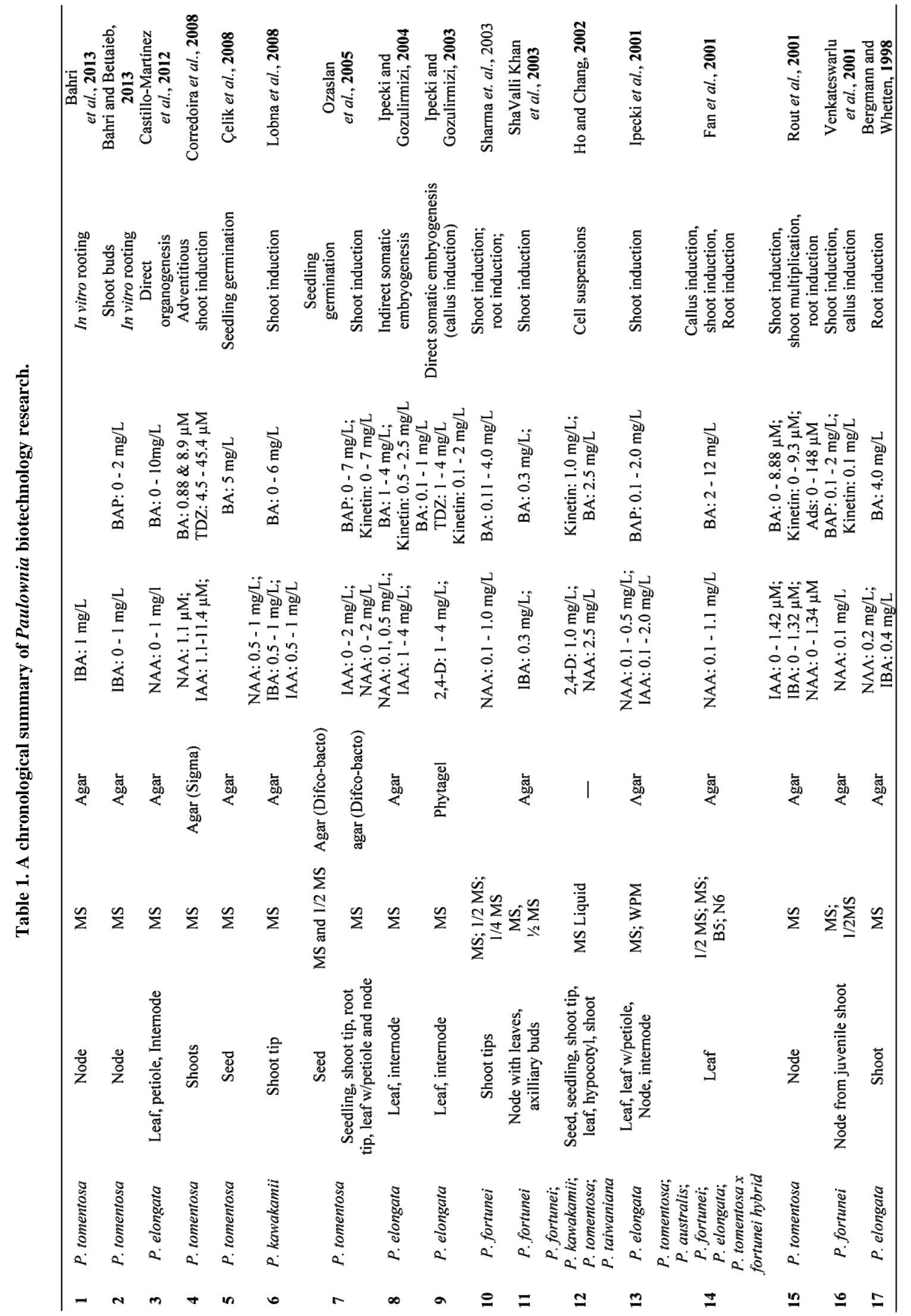




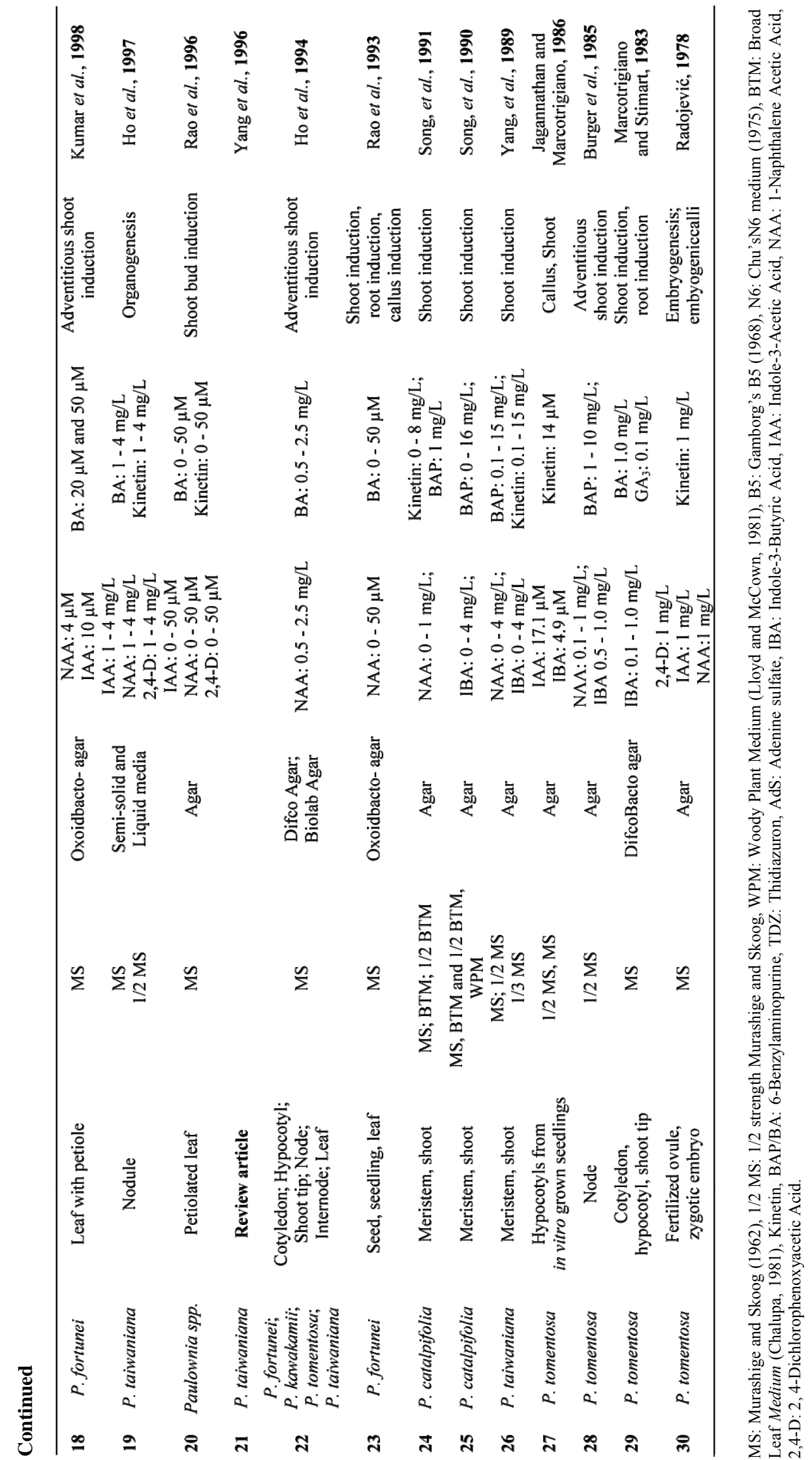


containing $1.0 \mathrm{mg} \cdot \mathrm{L}^{-1}$ activated charcoal [47]. Other explants including petioles, stems and leaves failed to produce an organogenic response on the same medium thereby underlying the importance of explant selection. Current research at FVSU includes shoot induction from leaf and seed explants. In addition, studies are underway to optimize thin cell layer (TCL) culture protocols for leaf and nodal explants. Murashige and Skoog (1962) [48] medium (MS) and woody plant medium (WPM) [49] have been widely used for Paulownia micropropagation with considerable success. Among various growth regulators studied, benzyl amino purine (BAP) is effective in most Paulownia species; however, specific species may exhibit variable responses. For instance, TDZ in combination with IAA produced the best regeneration response from $P$. tomentosa mature leaf explants [43]. Rooting in Paulownia, in general, is fairly easy as microcuttings can root efficiently in MS basal medium [50] without inclusion of an auxin. Production of hyperhydric shoots has been frequently observed during in vitro culture of several Paulownia species. A significant reduction in shoot hyperhydricity was achieved by adjusting culture medium conditions, especially gelling agent and sucrose concentrations [51]. Paulownia species is amenable to photoautotrophic culture exhibiting satisfactory shoot growth and spontaneous rooting [52,53]. The system takes advantage of chlorophyllous explant by placing it an environment conducive to photosynthesis by cutting down carbon source (sucrose) with $\mathrm{CO}_{2}$ enrichment. An exposure of $P$. tomentosa and $P$. fortunei nodal cultures to magnetic field enhanced adventitious shoot bud multiplication and improved plant regeneration while significantly reducing the amount of time required for obtaining whole plants [30,54].

Molecular studies aimed at understanding the mechanism of organogenesis in P. kawakamii reported differential expression of a cDNA encoding a putative bZIP transcription factor during multiple shoot proliferation [55]. Molecular dissection of the chronology of gene expression using Quantitative PCR revealed that only basal levels of transcripts were present in callus-forming tissues at day 0 and day 10 , whereas a six-fold increase in gene expression was seen in shoot-forming tissues at day 10, suggesting that $P K S F 1$ is associated with adventitious shoot bud development in Paulownia. Induction of polyploidy to obtain phenotypes with enlarged morphology and lower fertility has been successfully employed in Paulownia tomentosa using colchicine [56,57].

\subsection{Callus Initiation and Somatic Embryogenesis}

The first report of somatic embryogenesis in Paulownia was reported [58] using placental tissue of fertilized ovules as an explant. Zygotic embryos cultured on medium containing MS macro-, micronutrients and vitamins, $200 \mathrm{mg} \cdot \mathrm{L}^{-1}$ casein hydrolysate, $100 \mathrm{mg} \cdot \mathrm{L}^{-1}$ myoinositol, $10 \mathrm{mg} \cdot \mathrm{L}^{-1}$ pantothenic acid, $0.7 \%$ agar and IAA produced embryogenic callus; medium containing other growth regulators including 2,4-D and NAA produced non-embryogenic callus. Callus induced from fertilized ovular explants showed a persistent embryogenic capacity, eventually differentiating into embryos and plants. Callus induction was optimized in five Paulownia species (P. tomentosa, P. australis, P. fortunei, P. elongata, $P$. tomentosa $\times P$. fortunei) using leaf explants [31]. MS medium [48] containing varying levels of NAA (0.1 - 1.1 $\left.\mathrm{mg} \cdot \mathrm{L}^{-1}\right)$ and BAP $\left(2-12 \mathrm{mg} \cdot \mathrm{L}^{-1}\right)$ were tested for embryogenic culture induction and plant regeneration. Although five different media formulations were used, MS medium supplemented BAP and NAA produced an embryogenic response. Other Paulownia species tested elsewhere failed to produce an embryogenic response on the same medium composition suggesting a strong media $\times$ genotype interaction [40]. Direct and indirect somatic embryogenesis was observed from leaf and internode explants in $P$. elongata $[59,60]$. Somatic embryos were found suitable for synthetic seed production [59]. The technology assumes significance in terms of its utility for large-scale plant propagation in bioreactors, short- and long-term germplasm conservation, and easy transportation of planting stock material. Other reports on somatic embryogenesis and plant regeneration in $P$. elongata have been described $[4,27,31,61]$, but have been difficult to replicate using stated procedures.

Suspension cultures have great potential for screening and production of secondary metabolites in light of numerous medicinal phytochemicals occurring in Paulownia. Callus cultures of $P$. taiwaniana were obtained from leaf explants on MS medium supplemented with multiple plant growth regulators [37]. Histology and morphology analyses distinguished cultures as nodular cell aggregated of three distinct sizes, which eventually exhibited plant regeneration. Suspension cultures were produced by transferring such nodular aggregated to liquid medium with the same composition and maintained for over a year.

The protocol was modified to establish suspension cultures of four Paulownia species (P. fortunei, P. kawakamii, P. tomentosa, and P. taiwaniana). Seeds, germinated seedlings, shoot tips and leaves were directly cultured in liquid MS medium containing $1.0 \mathrm{mg} \cdot \mathrm{L}^{-1}$ 2,4-D and $0.1 \mathrm{mg} \cdot \mathrm{L}^{-1}$ kinetin [37]. Suspension cultures were obtained from all species tested but long-term maintenance (over one year) with frequent transfers to fresh medium was feasible only for $P$. taiwaniana and $P$. tomentosa. 


\subsection{Genetic Transformation}

Technology advances for in vitro propagation and improvement in genetic transformation protocols have accelerated the development of genetically engineered trees during the past 15 years. Targeted traits include herbicide tolerance, pest resistance, abiotic stress tolerance, modified fiber quality and quantity, and altered growth and reproductive development [62].

Genetic transformation of Paulownia has been achieved using both Agrobacterium-mediated transformation and biolistic bombardment $[61,63,64]$. In vitro shoots used for co-cultivation with Agrobacterium tumefaciens produced transgenic callus after transfer to induction medium. Hairy root production occurred in $33 \%$ shoot explants that were wounded by nicking and then co-cultivated with $A$. rhizogenes strain R1601. Hairy roots were observed from the site of explant wounding. Opine analyses demonstrated transgene expression in proliferating galls/hairy roots shortly after emergence from wound sites and in callus and roots after 12 weeks of in vitro culture [63]. Agrobacterium rhizogenes (LBA 9402 and A4 strains) was successfully used to induce eleven independent hairy root lines of Paulownia tomentosa by infecting stem explants. Transformation efficiency was dependent on explant age. Hairy root cultures grew rapidly in hormone-free Woody Plant liquid medium. Depending on the line used, the level of verbascoside varied from 1.7 to $8 \%$ of dry weight. Experiments with a high producing line PT-3 showed maximum verbascoside yield was achieved in half-strength Gamborg's B5 liquid medium being approximately double compared with the roots of 4.5-month-old-plants grown outside.

Biolistic bombardment of $P$. elongata leaf explants with a construct $\mathrm{pBI} 121$ harboring the $\beta$ glucuronidase (GUS) and neomycin phosphotransferase (NPT II) genes produced transgenic plants via organogenesis. Transgene insertion was demonstrated using PCR while expression was studied using fluorometric assay for GUS and paper chromatographic assay for NPT II. Optimizing transformation systems will greatly aid in the development of improved genotypes with rapid growth habits for lignocellulosic feedstock in future [61].

A MADS box transcription factor PkMADS1 regulating adventitious shoot bud induction was constitutively expressed in P. kawakamii using Agrobacterium-mediated transformation (strain GV3850). Transgenic plants were obtained by selection of proliferating shoots on medium supplemented with $10 \mathrm{mg} \cdot \mathrm{L}^{-1}$ kanamycin [35]. Paulownia shoots cultured in vitro exhibited a high sensitivity to kanamycin, thereby making it an effective selection agent for screening transgenic plants. Transgenic Paulownia plants expressing an antimicrobial Shiva-1 lytic peptide that encodes cecropin were produced using Agrobacterium-mediated transformation [65]. Enhanced resistance to a mycoplasms causing Witches' Broom disease was observed in transgenic plants. Another useful application of $A$. tumefaciens mediated gene transfer was the introduction of shiva-1 gene that produces cecropin peptides imparting increased resistance to mycoplasma causing Paulownia Witches' Broom disease [65].

Following development of genetic engineering protocols for tree species such as Paulownia, the next step in determining acceptability of transgene technology for forest tree improvement is to assess the adverse environmental impacts, if any, from field-release of genetically modified species. Ecological risks associated with commercial release range from transgene escape and introgression into wild gene pools, to the impact of transgene products on other organisms and ecosystem processes. Evaluation of those risks is confounded by the long life span of trees, and by limitations of extrapolating results from small-scale studies to larger-scale plantations.

\section{Medicinal Properties of Paulownia}

Polyphenolic compounds produced by plants as secondary metabolites exhibit high antioxidant activity [66]. Free radicals are implicated in several disorders in human body including atherosclerosis, central nervous system injury and gastritis $[67,68]$. Flavonoids with strong antioxidant properties inhibit hydrolytic and oxidative enzymes, prevent decomposition of peroxides into free radicals, act in anti-inflammatory pathways and minimize damage caused at the cellular level $[69,70]$. Plant-based antioxidants are used as therapeutics to supplement the human body's immune system [71]. A number of plant species in the Lamiaceae family including Basil (Ocimum spp.), Mint (Mentha spp.), Rosemary (Rosmarinus officinalis), Lavender (Lavandula spp.) and Baikal skullcap (Scutellaria baicalensis) [72,73] exhibit high total phenols and antioxidant activity [74,75]. Research on antioxidant properties and medicinal value of seconddary metabolites of Paulownia is gaining importance and lately many publications have appeared. Paulownia species are rich in phenolic substances distributed in different parts and tissues of the tree [76,77]. P. tomentosa leaves contain ursolic acid, and matteucinol. Xylem vessels contain paulownin, and d-sesamin while syringin and catalpinoside occur in bark extracts. Phytochemical screening of $P$. tomentosa var. tomentosa bark resulted in eight phenolic compounds through spectroscopic analysis [77]. Analysis of $P$. tomentosa fruits indicated presence of numerous $C$-geranyl compounds in ethanol fraction [78] that exhibited antiradical and cytoprotective activity when tested on Alloxan-induced diabetic mice [79]. Aqueous extract of Paulownia leaves and silage exhibit pronounced inhibitory activity against the Gram-negative bacteria in vitro [80]. Tablets and injections derived from 
Paulownia leaf, fruit and wood extracts are effective for bronchitis, especially relieving cough and reducing phlegm. Pharmacological experiments demonstrate utility of fruit extracts to relieve cough and asthma, and cause a reduction in blood pressure [2].

Fresh and dry leaves of $P$. elongata and $P$. fortunei, from FVSU experimental plots were used to conduct a comparative study on the antioxidant potential of leaf extracts. The colorimetric Folin-Ciocalteu reagent method [81] with modification [82] was used to measure total polyphenol (TPP) contents with gallic acid as a standard. Average TPP contents of fresh leaf extracts was $144.28 \mathrm{mg} / \mathrm{g}$ Gallic Acid Equivalent (GAE) (for P. elongata) and $207.53 \mathrm{mg} / \mathrm{g}$ GAE (P. fortunei) respectively, while the average TPP content ranged from $94.15 \mathrm{mg} / \mathrm{g}$ GAE ( $P$. elongata) to $266.74 \mathrm{mg} / \mathrm{g}$ GAE ( $P$. fortunei) (Figure 2).

\subsection{Antioxidant Capacity Measurement}

Additional studies were conducted to determine antioxidant capacity of leaf extracts of $P$. elongata and $P$. fortunei. ABTS (2, 2'-azinobis (3-ethylbenzothiazoline-6sulfonic acid) diammonium salt) is the chemical of choice used to measure the antioxidant capacity by the food industry and agricultural researchers. The ABTS radical cation is reactive towards most antioxidants including phenolics, thiols and Vitamin C. This assay is often referred to as the TROLOX (6-hydroxy-2, 5, 7, 8-tetramethychroman-2-carboxylic acid) equivalent antioxidant capacity (TEAC) assay. The reactivity of the various antioxidants in the leaf extracts are compared to that of TROLOX, which is a water-soluble analog of vitamin E. Antioxidant capacity calculation is based on inhibition exerted by TROLOX compared with sample mixed with diluted ABTS. A standard curve was generated for percent inhibition of TROLOX concentration in the range $300-1500 \mu \mathrm{M}$ with $\mathrm{R}^{2}=0.9935$. TEAC assay was carried out following the original protocol with minor modifications $[82,83]$.

The percent inhibition exhibited against TROLOX by these two species ranged from $48.84 \%$ to $97.53 \%$. $P$. elongata's fresh and dry leaf extract average inhibitions were $50.21 \%$ and $63.88 \%$ respectively and for $P$. fortunei it recorded $61.03 \%$ for fresh and $95.09 \%$ for dry extract in average inhibition against TROLOX. P. fortunei's average inhibition was among the highest of all percent inhibition. TEAC was calculated using a TROLOX standard curve. The TEAC values obtained ranged from $1255.30 \mu \mathrm{mol} / \mathrm{g}$ (dry extract of $P$. elongata) to $2377.10 \mu \mathrm{mol} / \mathrm{g}$ for $P$. fortunei dry extract (Figure 2).

The percent inhibition against TROLOX by two leaf extracts ranged between $48.84 \%$ to $97.53 \%$. P. elongata's fresh and dry leaf extract average inhibitions were $50.21 \%$ and $63.88 \%$ and for $P$. fortunei it recorded
$61.03 \%$ for fresh and $95.09 \%$ for dry extracts. P. fortunei's average inhibition for both fresh and dry leaf extracts were higher than $P$. elongata. The average TEAC values of fresh and dry leaf extracts of $P$. elongata was $1255.30 \mu \mathrm{mol} / \mathrm{g}$, and $1596.33 \mu \mathrm{mol} / \mathrm{g}$ respectively whereas for $P$. fortunei it was $1525.66 \mu \mathrm{mol} / \mathrm{g}$ and $2377.10 \mu \mathrm{mol} / \mathrm{g}$ (Figure 2).

\subsection{Estimation of Total Flavonoid Contents}

Estimation of total flavonoid content was conducted using aluminum chloride colorimetric method [84]. Quercetin dihydrate was used as a standard to make the calibration curve with concentrations ranging from $10-125$ $\mu \mathrm{g} / \mathrm{mL}$. The test solutions were prepared mixing fresh and dry leaf extracts with $10 \%$ aluminum chloride, $1 \mathrm{M}$ potassium acetate, $95 \%$ ethanol and distilled water, then absorption of the test solutions (for dry and fresh leaf extracts) were recorded using a spectrophotometer at 415 $\mathrm{nm}$. Once the readings were obtained, total flavonoid content was calculated and absorbance was plotted against $\mu \mathrm{g} / \mathrm{mL}$ where the relationship is linear and regression equation is determined by $\mathrm{y}=\mathrm{mx}+\mathrm{b}$. For each species, three independent replications were done and averaged. Flavonoid content in the fresh leaf extracts of P. elongata and P. fortunei were $102.58 \mu \mathrm{g} / \mathrm{mL}$ and $157.53 \mu \mathrm{g} / \mathrm{mL}$, respectively. In the extracts derived from dried leaves, flavonoid content of $P$. elongata was 104 $\mu \mathrm{g} / \mathrm{mL}$ whereas in case of $P$. fortunei it was at 158.45 $\mu \mathrm{g} / \mathrm{mL}$.

Out of three assays conducted, the results from total polyphenol concentration measurement and total flavonoid content exhibited a strong correlation (Figure 2(A)). As the TPP value increased, flavonoid content also increased. In addition, an increase in TPP caused a subsequent increase in TEAC values as well as flavonoid contents. Though results obtained in this study only establish the quantities available in fresh and dry extracts for TPP, TEAC and estimation of total flavonoid in general, it corroborates previous evidence for the antioxidant properties of specific bioactive compounds occurring in $P$. tomentosa [78].

\section{Future Prospects and Conclusions}

Forest biotechnology is an emerging field of interest. Existing protocols make it possible to genetically improve existing varieties using biotechnology. With the current economic importance and future uses of Paulownia species being developed, it is clear that plant regeneration using micropropagation is of paramount importance. Paulownia plants are now produced through tissue culture and shipped to domestic and international destinations. The potential for plant regeneration via organogenesis, from cotyledons and hypocotyls, as well as 

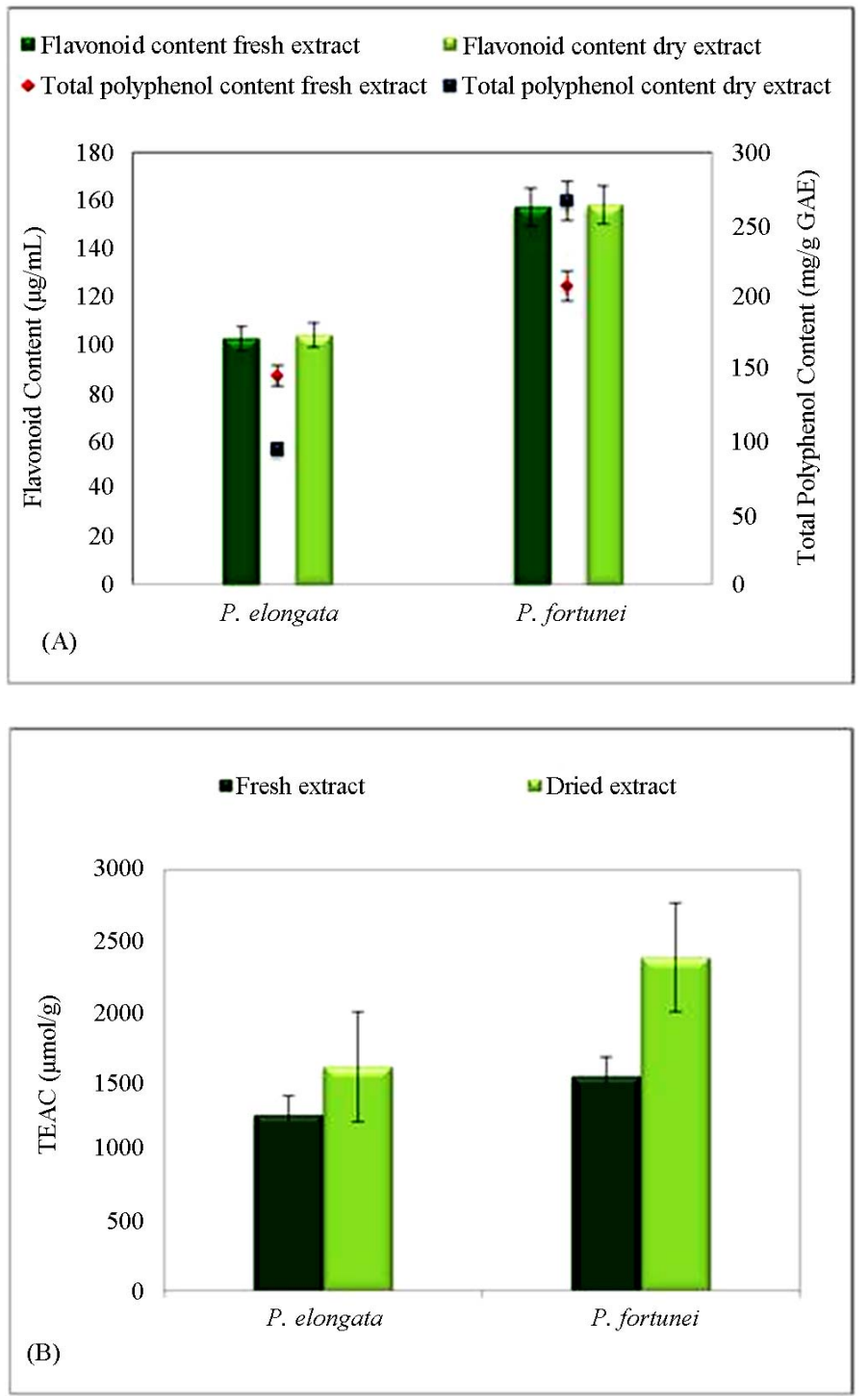

Figure 2. Paulownia leaf extract as a source of polyphenols with high antioxidant activity. (A) Correlation between total polyphenol and flavonoid content for fresh and dry extracts of $P$. elongata and $P$. fortunei, (B) TEAC value of extracts from fresh and dry leaf samples of $P$. elongata and $P$. fortunei. Values represent means of three replicates. The analysis of variance (ANOVA) single factor for fresh and dry extracts were performed to compare the means with significant differences between treatments at $\mathrm{p}<\mathbf{0 . 0 5}$ level.

determined requirements for rapid adventitious shoot generation from shoot tips, needs additional studies [85]. Although several techniques for plant regeneration have been described here, protocols for culture induction and plant regeneration from a number of explants including seed and roots are still lacking. Culture induction via Thin Cell Layer techniques also has not been widely documented. Lack of a reliable tissue culture would hinder downstream research applications such as genetic transformation, genomic and transcriptome analysis. A variety of techniques described in this review is a guideline, which lays a solid groundwork for additional studies by researchers.

The introduction of genes into plant cells and recovery of stable fertile transgenic plants is a viable alternative to conventional breeding techniques for making desired modifications in existing varieties. As gene isolation, characterization and genetic engineering technology become routine procedures, forest-tree species are becoming a major target for genetic improvement using molecular breeding [62]. The first genetically modified tree (Populus) was produced 20 years ago [85]. Despite this advance, the number of forest tree species for which transformation and regeneration techniques have been optimized remains low; they include aspen, cottonwood, eucalyptus and walnut. Recently, transformation and regeneration protocols have been developed for several gymnosperms, mostly species within the genera Pinus, 
Larix and Picea. For each of these species, only a few genotypes are known to be amenable to the recovery of transgenic plants. In general, effective plant regeneration has been more difficult to achieve through organogenesis than through somatic embryogenesis. Plant regeneration via somatic embryogenesis is a reliable method for genetic transformation since it has a single cell origin. The potential of cell suspension cultures for the production of somatic embryos offers a possibility of reducing time in obtaining synthetic seeds especially in case of woody tree species with a long seed generation time. Several forest trees (poplar, conifers) have been used for genetic manipulation and transgenic plants are being tested under field conditions. Ultimately, the real value of in vitro techniques lies in their extension and applications in forest-tree improvement programs.

Development of new drug is a complex, time-consuming, and an expensive process. The time taken from discovery of a new drug to its reaching the clinic is more than a decade, involving high financial commitment. Essentially, the new drug discovery involves the identification of new chemical entities (NCEs), having the required characteristic of druggability and medicinal chemistry. Many of these NCEs can be sourced through natural products (plants). Paulownia trees have been extensively used in many traditional medical systems in the East and a systematic study on their medicinal components and their activity holds promise for the health sector.

\section{Acknowledgements}

Paulownia research at Fort Valley State University (FVSU) is funded through Evans Allen grant (GEOX 5213) to NJ.

\section{REFERENCES}

[1] C. C. Freeman, R. K. Rabeler and W. J. Elisens, "Flora of North America, Provisional Publication," Vol. 17, 2012. http://floranorthamerica.org/files/Paulowniaceae04\%20SI .CH\%20for\%20web.pdf

[2] Z.-H. Zhu, C.-J. Chao, X.-Y. Lu and Y. G. Xiong, "Paulownia in China: Cultivation and Utilization," Asian Network for Biological Sciences and International Development Research Centre, Singapore, 1986, pp. 1-65.

[3] P. Li and J. Oda, "Flame Retardancy of Paulownia Wood and Its Mechanism," Journal of Material Science, Vol. 42, No. 20, 2007, pp. 8544-8550. http://dx.doi.org/10.1007/s10853-007-1781-9

[4] B. A. Bergmann and R. Whetten, "In Vitro Rooting and Early Greenhouse Growth of Micropropagated Paulownia elongata shoots," New Forests, Vol. 15, No. 2, 1998, pp. 127-138. http://dx.doi.org/10.1023/A:1006591704075

[5] S. El-Showk and N. El-Showk, "The Paulownia Tree: An Alternative for Sustainable Forestry," 2003.
http://www.cropdevelopment.org/docs/PaulowniaBrochur e_print.pdf

[6] W. C. Lin, "Trend of Worldwide Production of Paulownia," Taiwan Forestry, Vol. 1, No. 9, 1975, pp. 9-16.

[7] T. Vilsack, "Remarks by Agriculture Secretary Tom Vilsack on Biofuels as Prepared for Delivery," National Press Club, Washington DC, 2010.

[8] M. Beel, S. Davis, J. Murphy and P. Piper, "Product Potential of Paulownia Timber," Australian Forestry, Vol. 68 , No. 1, 2005, pp. 3-8. http://dx.doi.org/10.1080/00049158.2005.10676219

[9] F. Lopez, A. Perez, M. A. M. Zamudio, H. E. De Alva and J. C. Garcia, "Paulownia as Raw Material for Solid Biofuel and Cellulose Pulp," Biomass and Bioenergy, Vol. 45, 2012, pp. 77-86.

[10] B. Tisserat, N. Joshee, A. K. Mahapatra, G. W. Selling and V. L. Finkenstadt, "Physical and Mechanical Properties of Extruded Poly(lactic acid)-Based Paulownia elongata Bio-Composites," Industrial Crops and Products, Vol. 44, 2013, pp. 88-96. http://dx.doi.org/10.1016/j.indcrop.2012.10.030

[11] B. Tisserat, L. Reifschneider, N. Joshee and V. L. Finkenstadt, "Properties of High Density Polyethylene-Paulownia Wood Flour Composites via Injection Molding," BioResources, Vol. 8, No. 3, 2013, pp. 4440-4458.

[12] A. Kaymakci and A. Ayrilmis, "Surface Roughness and Wettability of Polypropylene Composites Filled with Fast-Growing Biomass: Paulownia elongata Wood," Journal of Composite Materials, 2013. http://dx.doi.org/10.1177/0021998313480199

[13] Q. Wang and J. F. Shogren, "Characteristics of the CropPaulownia System in China," Agriculture, Ecosystems \& Environment, Vol. 39, No. 3-4, 1992, pp. 145-152. http://dx.doi.org/10.1016/0167-8809(92)90050-L

[14] Z. Jiang, L. Gao, Y. Fang and X. Sun, "Analysis of Paulownia-Intercropping Types and Their Benefits in Woyang County of Anhui Province," Forest Ecology and Management, Vol. 67, No. 1-3, 1994, pp. 329-337. http://dx.doi.org/10.1016/0378-1127(94)90027-2

[15] Y. Song, "Nutritive Components of Paulownia Leaves as Fodder," Chemical Industry and Forest Products, Vol. 8, 1988, pp. 44-49.

[16] S. B. Carpenter, "This 'Princess' Heals Disturbed Land," American Forests, Vol. 83, 1977, pp. 22-23.

[17] B. A. Bergmann, A. R. Rubin and R. Campbell, "Potential of Paulownia elongata Trees for Swine Waste Remediation," Transactions of the ASAE, Vol. 40, No. 6, 1997, pp. 1733-1738.

[18] W. K. Clatterbuck and D. G. Hodges, "Tree Crops for Marginal Farmland. Paulownia," The University of Tennessee Extension, Knoxville, 2004, pp. 1-32.

[19] N. Joshee, "Paulownia: A Multipurpose Tree for Rapid Lignocellulosic Biomass Production," In: C. Kole, C. P. Joshi and D. Shonnard, Eds., Handbook of Bioenergy Crop Plants, Taylor \& Francis, Boca Raton, 2012, pp. 671-686. http://dx.doi.org/10.1201/b11711-31

[20] J. Maier and R. Vetter, "Biomass Yield and Fuel Charac- 
teristics of Short-Rotation Coppice (Willow, Poplar, Empress Tree)," Institute for Land Management Compatible to Environmental Requirements, 2004.

http://www.landwirtschaft-bw.info/servlet/PB/-s/1wc52ee jau6d25wkczz14b19drp219z/menu/110492112/index1109 769478375.html

[21] L. Jiménez, A. Rodriguez, J. L. Ferrer, A. Pérez and V. Angulo, "Paulownia, a Fast Growing Plant, as a Raw Material for Paper Manufacturing," Afinidad, Vol. 62, No. 516, 2005, pp. 100-105.

[22] S. B. Carpenter, M. J. Immel and N. D. Smith, "Effect of Photoperiod on the Growth and Photosynthetic Capacity of Paulownia Seedlings," Castanea, Vol. 48, No. 1, 1983, pp. 13-18.

[23] M. Angelova-Romova, A. Koleva, G. Antova, M. Zlatanov, M. Stoyanova, K. Dobreva, P. Denev, S. Damianova, B. Angelov and A. Stoyanova, "Lipid Composition of Paulownia Seeds Grown in Bulgaria," Trakya University Journal of Sciences, Vol. 13, No. 2, 2011, pp. 101-111.

[24] B. A. Bergmann and H.-K. Moon, "Adventitious Shoot Production in Paulownia," Plant Cell Reports, Vol. 16, No. 5, 1997, pp. 315-319.

[25] S. L. Song, T. Sato, K. Ishii, A. Saito and K. Ohba, "In Vitro Mass Propagation by Meristem Culture of Two Mature Trees of Paulownia catalpifolia," Journal of the Japanese Forestry Society, Vol. 72, No. 6, 1990, pp. 495498.

[26] S. L. Song, K. Suda, K. Ishii, A. Saito and K. Ohba, "Plantlet Regeneration from Leaf and Petiole Explants of in Vitro Cultured Paulownia catalpifolia," Journal of the Japanese Forestry Society, Vol. 73, No. 1, 1991, pp. 6063.

[27] Z. Ipekci, A. Altinkut, K. Kazan, K. Bajrovic and N. Gozukirmizi, "High Frequency Plant Regeneration from Nodal Explants of Paulownia elongata," Plant Biology, Vol. 3, No. 2, 2001, pp. 113-115. http://dx.doi.org/10.1055/s-2001-12903

[28] C. R. Castillo-Martínez, M. A. Gutiérrez-Espinosa, M. T. Buenrostro-Nava, V. M. C. Alcalá and J. C. Iñiguez, "Regeneration of Paulownia elongata Steud. Plants by Direct Organogenesis," Journal of Forestry, Vol. 3, No. 10, 2012, pp. 41-49.

[29] M. Ozaslan, C. Can and T. Aytekin, "Effect of Explant Source on In vitro Propagation of Paulownia tomentosa Steud," Biotechnology and Biotechnological Equipment, Vol. 19, No. 3, 2005, pp. 20-26.

[30] Ö. Çelik, Ç. Atak and A. Rzakulieva, "Stimulation of Rapid Regeneration by a Magnetic Field in Paulownia Node Cultures," Journal of Central European Agriculture, Vol. 9, No. 2, 2008, pp. 297-304.

[31] G.-Q. Fan, X.-Q. Zhai, C.-J. Zhai and H.-T. Bi, "Callus Induction from Leaves of Different Paulownia Species and Its Plantlet Regeneration," Journal of Forestry Research, Vol. 12, No. 4, 2001, pp. 209-214. http://dx.doi.org/10.1007/BF02856709

[32] P. P. Kumar, C. D. Rao and C.-J. Goh, "Influence of Petiole and Lamina on Adventitious Shoot Initiation from Leaf Explants of Paulownia fortunei," Plant Cell Reports,
Vol. 17, No. 11, 1998, pp. 886-890. http://dx.doi.org/10.1007/s002990050503

[33] B. Venkateswarlu, J. Mukhopadhyay, E. Sreenivasan and V. M. Kumar, "Micropropagation of Paulownia fortuneii through in Vitro Axillary Shoot Proliferation," Indian Journal of Experimental Biology, Vol. 39, No. 6, 2001, pp. 594-599.

[34] C. D. Rao, C.-J. Goh and P. P. Kumar, "High Frequency Plant Regeneration from Excised Leaves of Paulownia fortunei," In Vitro Cellular \& Developmental BiologyPlant, Vol. 29, No. 2, 1993, pp. 72-76. http://dx.doi.org/10.1007/BF02632255

[35] A. P. Prakash and P. P. Kumar, "PkMADS1 Is a Novel MADS Box Gene Regulating Adventitious Shoot Induction and Vegetative Shoot Development in Paulownia kawakamii," The Plant Journal, Vol. 29, No. 2, 2002, pp. 141-151.

http://dx.doi.org/10.1046/j.0960-7412.2001.01206.x

[36] S. T. Lobna, M. M. S. Ibrahim and M. M. Farahat, "A Micropropagation Protocol of Paulownia kawakamii through in Vitro Culture Technique," Australian Journal of Basic and Applied Sciences, Vol. 2, No. 3, 2008, pp. 594-600.

[37] C.-H. Ho and S.-H. Chang, "A Rapid Method to Establish Suspension Cultures of Paulownia Species," Taiwan Journal of Forest Science, Vol. 17, No. 4, 2002, pp. 421427.

[38] C.-K. Ho and G. Jacobs, "Occurrence and Recovery of Vitrification in Tissue Cultures of Paulownia Species," Bulletin of Taiwan Forestry Research Institute, Vol. 10, No. 4, 1995, pp. 391-403.

[39] J. C. Yang, S. H. Chang and C. K. Ho, "Micropropagation of Paulownia taiwaniana from Mature Tissues," Annals of Forest Science, Vol. 46, 1989, pp. 165-167. http://dx.doi.org/10.1051/forest:19890538

[40] J. C. Yang, C.-K. Ho, Z.-Z. Chen and S.-H. Cheng, "Paulownia x taiwaniana (Taiwan Paulownia)," In: Y. P. S. Bajaj, Ed., Biotechnology in Agriculture and Forestry, Vol. 35, Springer-Verlag, Berlin, 1996, pp. 273-289.

[41] C. K. Ho, Z. Z. Chen, J. Y. Tsai and J. C. Yang, "Nodule Culture of Paulownia x taiwaniana," Taiwan Journal of Forestry Science, Vol. 12, No. 1, 1997, pp. 39-45.

[42] M. Marcotrigiano and D. P. Stimart, "In Vitro Organogenesis and Shoot Proliferation of Paulownia tomentosa Steud. (Empress Tree)," Plant Science Letters, Vol. 31, No. 2-3, 1983, pp. 303-310. http://dx.doi.org/10.1016/0304-4211(83)90069-X

[43] E. Corredoira, A. Ballester and A. Vieitez, "ThidiazuronInduced High-Frequency Plant Regeneration from Leaf Explants of Paulownia tomentosa Mature Trees," Plant Cell, Tissue and Organ Culture, Vol. 95, No. 2, 2008, pp. 197-208. http://dx.doi.org/10.1007/s11240-008-9433-6

[44] D. W. Burger, L. Liu and L. Wu, "Rapid Micropropagation of Paulownia tomentosa," HortScience, Vol. 20, No. 4, 1985, pp. 760-761.

[45] G. R. Rout, G. M. Reddy and P. Das, "Studies on in Vitro Clonal Propagation of Paulownia tomentosa STEUD," and Evaluation of Genetic Fidelity through RAPD 
Marker," SilvaeGenetica, Vol. 50, No. 5-6, 2001, pp. 208212.

[46] C. D. Rao, C.-J. Goh and P. P. Kumar, "High Frequency Adventitious Shoot Regeneration from Excised Leaves of Paulownia spp. Cultured in Vitro," Plant Cell Reports, Vol. 16, No. 3-4, 1996, pp. 204-209.

http://dx.doi.org/10.1007/BF01890868

[47] M. U. Nguyen, X. D. Thai and V. L. Bui, "Effects of Plant Growth Regulators on Callus Induction and Shoot Regeneration of Paulownia fortunei," Tap Chi Congnghe Sinh Hoc, Vol. 3, No. 4, 2005, pp. 479-485.

[48] T. Murashige and F. Skoog, "A Revised Medium for Rapid Growth and Bio Assays with Tobacco Tissue Cultures," Physiologia Plantarum, Vol. 15, No. 3, 1962, pp. 473-497.

http://dx.doi.org/10.1111/j.1399-3054.1962.tb08052.x

[49] G. Lloyd and B. McCown, "Commercially Feasible Micropropagation of Mountain laurel, Kalmia latifolia, by Use of Shoot Tip Culture," Proceedings of the International Plant Propagators Society, Vol. 30, 1981, pp. 421427.

[50] N. B. Bahri and T. Bettaieb, "In Vitro Propagation of a Forest Tree Paulownia tomentosa (Thunb.) Steud.-A Valuable Medicinal Tree Species," Albanian Journal of Agricultural Science, Vol. 12, No. 1, 2013, pp. 37-42.

[51] C-K. Ho, and G. Jacobs, "Occurrence and Recovery of Vitrification in Tissue Cultures of Paulownia Species," Bulletin Taiwan Forestry Research Institute, New Series, Vol. 10, 1995, pp. 391-403.

[52] T. Kozai and C. Kubota, "Developing a Photoautotrophic Micropropagation System for Woody Plants," Journal of Plant Research, Vol. 114, No. 4, 2001, pp. 525-537. http://dx.doi.org/10.1007/PL00014020

[53] P. S. ShaValli Khan, T. Kozai, Q. T. Nguyen, C. Kubota and V. Dhawan, "Growth and Water Relations of Paulownia fortunei under Photomixotrophic and Photoautotrophic Conditions," Biologia Plantarum, Vol. 46, No. 2, 2003, pp. 161-166.

http://dx.doi.org/10.1023/A:1022844720795

[54] O. Yaycili and S. Alikamanoglu, "The Effect of Magnetic Field on Paulownia Tissue Cultures," Plant Cell, Tissue and Organ Culture, Vol. 83, No. 1, 2005, pp. 109-114. http://dx.doi.org/10.1007/s11240-005-4852-0

[55] R. K. Low, A. P. Prakash, S. Swarup, C.-J. Goh and P. P. Kumar, "A Differentially Expressed bZIP Gene is Associated with Adventitious Shoot Regeneration in Leaf Cultures of Paulownia kawakamii," Plant Cell Reports, Vol. 20, No. 8, 2001, pp. 696-700. http://dx.doi.org/10.1007/s00299-001-0401-4

[56] L. Jagannathan and M. Marcotrigiano, "Phenotypic and Ploidy Status of Paulownia tomentosa Trees Regenerated from Cultured Hypocotyls," Plant Cell Tissue and Organ Culture, Vol. 7, No. 3, 1986, pp. 227-236. http://dx.doi.org/10.1007/BF00037739

[57] Z.-Q. Tang, D.-L. Chen, Z.-J. Song, Y.-C. He and D.-T. Cai, "In Vitro Induction and Identification of Tetraploid Plants of Paulownia tomentosa," Plant Cell, Tissue and Organ Culture, Vol. 102, No. 2, 2010, pp. 213-220. http://dx.doi.org/10.1007/s11240-010-9724-6

[58] L. Radojević, "Somatic Embryos and Plantlets from Callus Cultures of Paulownia tomentosa STEUD.," Zeitschrift fur Pflanzenphysiologie, Vol. 91, No. 1, 1979, pp. 57-62.

[59] Z. Ipekci and N. Gozukirmizi, "Direct Somatic Embryogenesis and Synthetic Seed Production from Paulownia elongata," Cell Biology and Morphogenesis, Vol. 22, No. 1, 2003, pp. 16-24.

[60] Z. Ipekci and N. Gozukirmizi, "Indirect Somatic Embryogenesis and Plant Regeneration from Leaf and Internode Explants of Paulownia elongata," Plant Cell, Tissue and Organ Culture, Vol. 79, No. 3, 2005, pp. 341-345. http://dx.doi.org/10.1007/s11240-003-4632-7

[61] O. Castellanos-Hernández, A. Rodríguez-Sahagún, G. Acevedo-Hernández, B. Rodríguez-Garay, J. CabreraPonce and L. Herrera-Estrella, "Transgenic Paulownia elongata S. Y. Hu Plants Using Biolistic-Mediated Transformation," Plant Cell, Tissue and Organ Culture, Vol. 99, No. 2, 2009, pp. 175-181. http://dx.doi.org/10.1007/s11240-009-9590-2

[62] M. Hinchee, W. Rottmann, L. Mullinax, C. Zhang, S. Chang, M. Cunningham, L. Pearson and N. Nehra, "ShortRotation Woody Crops for Bioenergy and Biofuels Applications," In Vitro Cellular Development BiologyPlant, Vol. 45, No. 6, pp. 2009, 619-629.

[63] B. A. Bergmann, X. Lin and R. Whetten, "Susceptibility of Paulownia elongata to Agrobacterium and Production of Transgenic Calli and Hairy Roots by in Vitro Inoculation," Plant Cell, Tissue and Organ Culture, Vol. 55, No. 1, 1999, pp. 45-51. http://dx.doi.org/10.1023/A:1026481926560

[64] K.-L. Ku, C.-F. Hsu and Y.-K. Liao, "Production of Acteoside in Hairy-Root Culture of Paulownia fortunei Hemsl." Taiwan Journal of Forest Science, Vol. 27, No. 1, 2012, pp. 13-29.

[65] T. Du, Y. Wang, Q.-X. Hu, J. Chen, S. Liu, W.-J. Huang and M.-L. Lin, "Transgenic Paulownia Expressing Shiva-1 Gene Has Increased Resistance to Paulownia Witch's Broom Disease", Journal of Integrative Plant Biology, Vol. 47, No. 12, 2005, pp. 1500-1506. http://dx.doi.org/10.1111/j.1744-7909.2005.00168.x

[66] A. Rohman, S. Riyanto, N. Yuniarti, W. R. Saputra, R. Utami and W. Mulatsih, "Antioxidant Activity, Total Phenolic, and Total Flavonoid of Extracts and Fractions of Red Fruit (Pandanus conoideus Lam.)," International Food Research Journal, Vol. 17, No. 1, 2010, pp. 97-106.

[67] J. T. Kumpulainen and J. T. Salonen, "Natural Antioxidants and Anticarcinogens in Nutrition, Health and Disease," Royal Society of Chemistry, London, 1999, pp. 178-187. http://dx.doi.org/10.1533/9781845698409

[68] F. Pourmorad, S. J. Hosseinimehr and N. Shahabimajd, "Antioxidant Activity, Phenol and Flavonoid Contents of Some Selected Iranian Medicinal Plants," African Journal of Biotechnology, Vol. 5, No. 11, 2006, pp. 1142-1145.

[69] E. Frankel, "Nutritional Benefits of Flavonoids," International Conference on Food Factors: Chemistry and Cancer Prevention, Hamamatsu, 10-15 December 1995, Article ID: C6-2. 
[70] H. Li, Z. Hao, X. Wang, L. Huang and J. Li, "Antioxidant Activities of Extracts and Fractions from Lysimachia foenum-graecum Hance," Bioresources Technology, Vol. 100, No. 2, 2009, pp. 970-974.

http://dx.doi.org/10.1016/j.biortech.2008.07.021

[71] P. Schuler, "Natural Antioxidants Exploited Commercially," In: B. J. F. Hudson, Ed., Food Antioxidants, Elsevier, London, 1990, pp. 99-170.

[72] Z. H. Shao, T. L. VandenHoek, C.-Q. Li, P. T. Schumacker, L. B. Becker, K. C. Chan, Y. Qin, J.-J. Yin and C.-S.Yuan, "Synergistic Effect of Scutellaria baicalensis and Grape Seed Proanthocyanidins on Scavenging Reactive Oxygen Species in Vitro," American Journal of Chinese Medicine, Vol. 32, No. 1, 2004, pp. 89-95. http://dx.doi.org/10.1142/S0192415X04001722

[73] V. Y. Waisundara, "Evaluation of the Antioxidant Activity of Scutellaria baicalensis and its Constituents in Diabetic Rats," Thesis for the Degree of Doctor of Philosophy, National University of Singapore, Singapore, 2010, $174 \mathrm{p}$.

[74] W. Zheng and S. Y. Wang, "Antioxidant Activity and Phenolic Compounds in Selected Herbs," Journal of Agriculture and Food Chemistry, Vol. 49, No. 11, 2001, pp. 5165-5170. http://dx.doi.org/10.1021/jf010697n

[75] M. Atanassova and S. Georgieva, "Comparative Polyphenol Composition and Antioxidant Capacity of the Bulgarian Plants (Dry Herbs)," Electronic Journal of Environmental, Agricultural and Food Chemistry, Vol. 9, No. 9, 2010, pp. 1514-1523.

[76] K. Šmejkal, P. Holubova, A. Zima, J. Muselik and M. Dvorska, "Antiradical Activity if Paulownia tomentosa (Scrophulariaceae) Extracts," Molecules, Vol. 12, No. 6, 2007, pp. 1210-1219. http://dx.doi.org/10.3390/12061210

[77] C.-L. Si, S.-C. Liu, H.-Y. Hu, J.-Z. Jiang, G.-J. Yu, X.-D. Ren and G.-H. Xu, "Activity Guided Screening of the Antioxidants from Paulownia tomentosa var. tomentosa Bark," Bioresources, Vol. 8, No. 1, 2013, pp. 628 -637.

[78] K. Šmejkal, L. Grycová, R. Madek, F. Lemière, D. Jankovská, H. Forejtníková, J. Vančo and V. Suchý, " $C$ -
Geranyl Compounds from Paulownia tomentosa Fruits," Journal of Natural Products, Vol. 70, No. 8, 2007, pp. 1244-1248. http://dx.doi.org/10.1021/np070063w

[79] A. Zima, J. Hošek, J. Treml, J. Muselík, P. Suchý, A. Lopes and M. Žemlička, "Antiradical and Cytoprotective Activities of Several C-Geranyl-substituted Flavanones from Paulownia tomentosa Fruit," Molecules, Vol. 15, No. 9, 2010, pp. 6035-6049. http://dx.doi.org/10.3390/molecules15096035

[80] T. P. Popova and B. D. Baykov, "Antimicrobial Activity of Aqueous Extracts of Leaves and Silage from Paulownia elongata," American Journal of Biological, Chemical and Pharmaceutical Sciences, Vol. 1, No. 2, 2013, pp. 8-15.

[81] O. H. Lowry, N. J. Rosebrough, A. L. Farr and R. J. Randall, "Protein Measurement with the Folin Phenol Reagent," Journal of Biological Chemistry, Vol. 193, No. 1, 1951, pp. 265-275.

[82] W. Yi and H. Wetzstein, "Biochemical, Biological and Histological Evaluation of Some Culinary and Medicinal Herbs Grown Under Greenhouse and Field Conditions," Journal of the Science of Food and Agriculture, Vol. 90, No. 6, 2010, pp. 1063-1070.

[83] R. Re, N. Pellegrini, A. Proteggente, A. Pannala, C. Yang and M. Rice-Evans, "Antioxidant Activity Applying an Improved ABTS Radical Cation Decolorization Assay," Free Radical Biology and Medicine, Vol. 26, No. 9-10, 1999, pp. 1231-1237. http://dx.doi.org/10.1016/S0891-5849(98)00315-3

[84] C.-C. Chang, M.-H. Yang, H.-M. Wen and J.-C. Chern, "Estimation of Total Flavonoid Content in Propolis by Two Complementary Colorimetric Methods," Journal of Food and Drug Analysis, Vol. 10, No. 3, 2002, pp. 178182.

[85] J. J. Fillatti, J. Sellmer, B. McCown and L. Comai, "Agrobacterium-Mediated Transformation and Regeneration of Populus," Molecular Genomics and Genetics, Vol. 206, No. 2, 1987, pp. 192-196. http://dx.doi.org/10.1007/BF00333574 